\title{
An efficient asymmetric synthesis of (-)-wodeshiol
}

\author{
SOON HO LEE ${ }^{\mathrm{a}}$, JAE-CHUL JUNG ${ }^{\mathrm{b}}$ and OEE SOOK PARK ${ }^{\mathrm{c}, *}$ \\ a Department of Chemistry, Institute for Basic Sciences, College of Natural Sciences, \\ Chungbuk National University, Cheongju 361-763, Chungbuk, Korea \\ ${ }^{\mathrm{b}}$ Department of Neuroscience and Medical Research Institute, School of Medicine, \\ Ewha Woman's University, Seoul 158-710, Korea \\ ${ }^{c}$ Department of Herb Industry/Herb Resources Jungwon University, 85 Munmu-ro, Goesan-eup, Goesan-gun, \\ Chungbuk, 367-805, Korea \\ e-mail: ospark@jwu.ac.kr
}

MS received 19 December 2010; accepted 30 March 2011

\begin{abstract}
An efficient synthesis of (-)-wodeshiol 1 is described. The key reactions include highly stereoselective aldol condensation of piperonal with the dianion of chiral oxazolidinone, subsequent intramolecular ring cyclization of the aldol product $\mathbf{8}$ and a diastereocontrolled oxygenation of dilactone $\mathbf{7}$ in good yield.
\end{abstract}

Keywords. (-)-Wodeshiol; stereoselective aldol condensation; diastereocontrolled oxygenation; intramolecular ring cyclization.

\section{Introduction}

Furofuran lignans have stimulated significant interest due to their wide range of intriguing biological activities ${ }^{1}$ such as antitumor, ${ }^{2}$ antimitomic, ${ }^{3}$ antiviral, ${ }^{4}$ antioxidant,${ }^{5}$ antihypertensive, ${ }^{6}$ inhibition of plateletactivating factor (PAF), ${ }^{7}$ and $\mathrm{Ca}^{2+}$ channels, ${ }^{8}$ cAMP phosphodiesterase inhibitory, ${ }^{9}$ sodium selective diuretic properties, ${ }^{10}$ and microsomal monooxygenases inhibitory effects for insects. ${ }^{11}$ Of the furofurans, these compounds containing 4 contiguous stereogenic centers and one or two tertiary hydroxy functions at the bridgehead position such as $(-)$-wodeshiol $\mathbf{1},{ }^{12}(+)$-paulownin $\mathbf{2},{ }^{13}(+)$-isogmelinol $\mathbf{3},{ }^{14}(+)$-isopaulownin $\mathbf{4},{ }^{13}$ and (+)gmelinol $\mathbf{5},{ }^{15}$ have generated considerable and continued interest due to their unique structural characteristics and stereochemical diversity (figure 1). The only synthesis published for (-)-wodeshiol $\mathbf{1}$ is that of Corey and $\mathrm{Han}^{16}$ who synthesized it from the $\alpha, \beta$-enone using a chiral oxazaborolidine for catalytic control of absolute configuration.

(-)-Wodeshiol 1 was isolated from Cleistanthus collinus or Kigelia pinnata by Anjaneyulu group ${ }^{17}$ and Inoue group, ${ }^{18}$ respectively. These spectra indicated the equatorial disposition of the two aryl groups and

\footnotetext{
${ }^{*}$ For correspondence
}

showed that positions $\mathrm{C}-1$ and $\mathrm{C}-5$ with dihydroxyl group. In preliminary communications, ${ }^{19}$ we reported a method for efficient synthesis of furofuran lignans using highly stereoselective aldol condensation of piperonal and intramolecular ring cyclization of aldol product. As part of our continuing interest in the asymmetric synthesis of furofuran lignans for potential use as anticancer and anti-inflammatory agents, we established a stereoselective aldol condensation and a diastereocontrolled oxygenation to accomplish asymmetric synthesis of (-)-wodeshiol 1. In this report, we describe an efficient asymmetric synthesis of (-)-wodeshiol 1 through 3 step route from the key starting material dilactone.

\section{Results and discussion}

The retrosynthetic analysis for (-)-wodeshiol $\mathbf{1}$ is summarized in scheme 1 . We envisioned that (-)-wodeshiol 1 could be synthesized from the key intermediate 7 in 3 steps, which has been prepared, during our synthesis of (+)-sesamin and (-)-sesamin. ${ }^{20}$ This precursor was synthesized by intramolecular ring cyclization of chiral complex $\mathbf{8}$ which was derived from piperonal and 1,4-bis-[4-(S)-benzyl-2-oxo-oxazolidin3-yl]butane-1,4-dione through a diastereoselective double aldol condensation in the presence of dibutylboron triflate. The diastereocontrolled oxygenation of inter- 


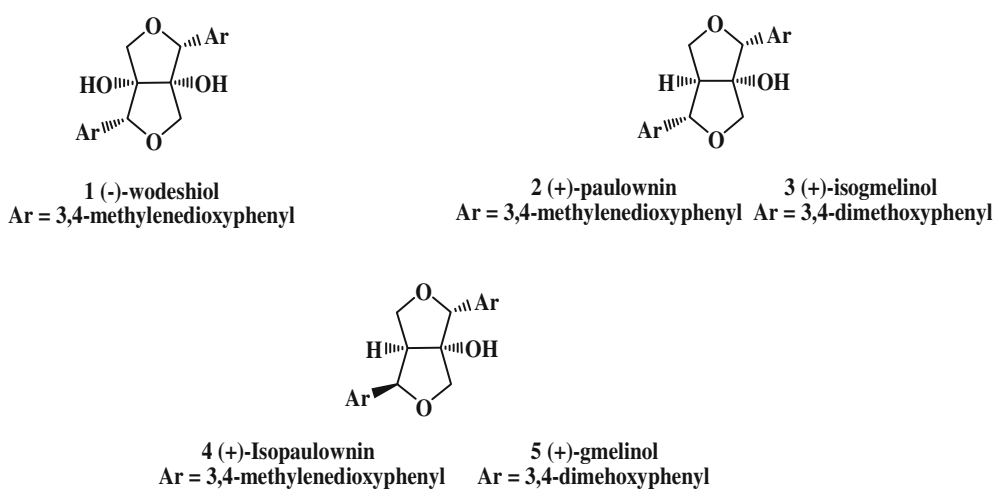

Figure 1. Structures of furofuran lignans with tertiary hydroxy function at the bridge-head position.<smiles>O[C@]12CO[C@@H](c3ccc4c(c3)OCO4)[C@@]1(O)CO[C@H]2c1ccc2c(c1)OCO2</smiles>

(-)-Wodesshiol 1<smiles>O=C1O[C@@H](c2ccc3c(c2)OCO3)[C@H]2C(=O)O[C@H](c3ccc4c(c3)OCO4)[C@@H]12</smiles><smiles>O=C1O[C@H](c2ccc3c(c2)OCO3)[C@]2(O)C(=O)O[C@H](c3ccc4c(c3)OCO4)[C@@]12O</smiles>

6

Scheme 1. Retrosynthetic analysis of (-)-wodeshiol 1.

mediate 7 would give the compound 6 which has two -OH groups at $\alpha$ position of bridge-head carbon. Reduction of compound 6 with DIBAL-H, followed by removal of the dihydroxyl groups of the dihydroxy dilactol 12 would give (-)-wodeshiol 1.

The synthesis of (-)-wodeshiol $\mathbf{1}$ was accomplished as depicted in scheme 2 . The key intermediate 7 was prepared according to the reactions as those used for the synthesis of $(+) /(-)$-sesamin. ${ }^{20}$ Aldol condensation of boron $(Z)$-enolate $^{21}$ (generated by treatment of $N$ acyloxazolidinone $\mathbf{1 0}$ with dibuthylboron triflate ${ }^{22}$ and DIPEA in $\mathrm{CH}_{2} \mathrm{Cl}_{2}$ at $-78^{\circ} \mathrm{C}$ ) and piperonal afforded the condensation product $\mathbf{1 1}$ as an unstable intermediate, which was not isolated but instead subjected to intramolecular ring cyclization $\left[\mathrm{KH}_{2} \mathrm{PO}_{4}\right.$ and $\mathrm{H}_{2} \mathrm{O}_{2}$ $(28 \%)$ in $\mathrm{MeOH}$ ] to give dilactone 7 with 95:5 diastereomeric selectivity, which was determined on the basis of HPLC analysis (91\% combined yield for two steps). The diastereocontrolled oxygenation ${ }^{23}$ of dilactone 7 with MoOPH produced dihydroxy dilactone 6 in 58\% yield. Interestingly, dihydroxy dilactone $\mathbf{6}$ was treated with benzyl bromide in the presence of bases such as $\mathrm{NaH}(60 \%), \mathrm{K}_{2} \mathrm{CO}_{3}$, or DIPEA to generate benzyl protected compound. Unfortunately, these reactions failed to give desired product, giving starting material and/or mono-protected product. Reduction of the dihydroxy dilactone 6 with DIBAL-H yielded dihydroxy dilactol 12 (1:1 cis/trans ratio, $65 \%$ combined yield). The dihydroxy dilactol 12 was reduced by treatment with $\mathrm{Et}_{3} \mathrm{SiH}$ and $\mathrm{BF}_{3} \cdot \mathrm{Et}_{2} \mathrm{O}$ in $\mathrm{CH}_{2} \mathrm{Cl}_{2}$ to give (-)-wodeshiol 1 in 58\% yield. (-)-Wodeshiol 1 could neither be acetylated in the usual way with $\mathrm{Ac}_{2} \mathrm{O}$ /pyridine nor oxidized with Jones reagent. However, acetylation of (-)wodeshiol 1 with $\mathrm{Ac}_{2} \mathrm{O}$ /triethylamine in the presence of 
<smiles>CC(C)[C@H]1COC(=O)N1C(=O)CCC(=O)N1C(=O)OC[C@H]1[18CH]</smiles>

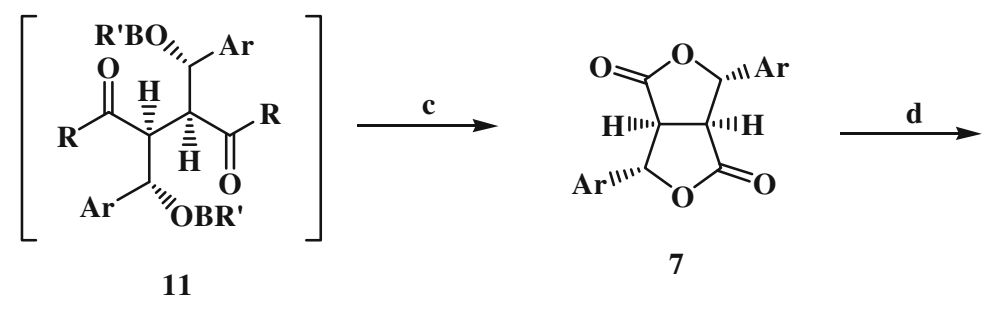<smiles>CC(C)CC(C)C</smiles>

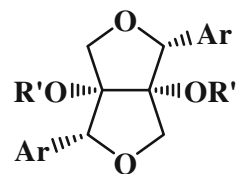

$\mathrm{g} \square \mathbf{1} \mathbf{R}^{\prime}=\mathbf{H},(-)$-Wodeshiol

$13 R^{\prime}=A c$

Ar: Methylenedioxyphenyl

Scheme 2. Reagents and conditions: (a) $n$-BuLi, succinyl chloride/THF, $0^{\circ} \mathrm{C}, 2 \mathrm{~h}, 86 \%$; (b) $\mathrm{Bu}_{2} \mathrm{BOTf}$, DIPEA/ $\mathrm{CH}_{2} \mathrm{Cl}_{2},-78^{\circ} \mathrm{C}$, piperonal, 20 min; (c) $\mathrm{KH}_{2} \mathrm{PO}_{4}(\mathrm{aq}), \mathrm{H}_{2} \mathrm{O}_{2}(28 \%) / \mathrm{MeOH}, \mathrm{rt}, 8 \mathrm{~h}, 88 \%$ (two steps); (d) LDA, MoOPH/THF, $-78^{\circ} \mathrm{C}, 4 \mathrm{~h}, 58 \%$; (e) DIBAL-H/THF, $-25^{\circ} \mathrm{C}, 8 \mathrm{~h}, 65 \%$; (f) $\mathrm{Et}_{3} \mathrm{SiH}, \mathrm{BF} 3 \cdot \mathrm{Et}_{2} \mathrm{O} / \mathrm{CH}_{2} \mathrm{Cl}_{2},-40^{\circ} \mathrm{C}, 5 \mathrm{~h}, 58 \%$; (g) $\mathrm{Ac}_{2} \mathrm{O}$, TEA, DMAP, rt, $2 \mathrm{~h}, 65 \%$.

4-dimethylaminopyridine (DMAP) gave diacetate $\mathbf{1 3},{ }^{24}$ which could be easily isolated and characterized.

\section{Conclusion}

In conclusion, a new and efficient method have been developed for the synthesis of (-)-wodeshiol 1 via a five-step route using a diastereocontrolled oxygenation in overall $10.4 \%$ yield. This synthetic method is better than the reported one in view of simplicity, enantiomeric excess and overall yield and should be useful in the synthesis of furofuran lignan which has two tertiary hydroxly groups at bride-head carbon.

\section{Acknowledgement}

This work was supported by the Korea Research Foundation Grant funded by the Korean Government (KRF2006-531-C00035).

\section{References}

1. Ward R S 1982 Chem. Soc. Rev. 1175

2. Teles H L, Hemerly J P, Paulettit P M, Pandolfi J R C, Araujot A R, Valentini S R, Young M C M, Bolzani V S, Silva D H S 2005 Nat. Prod. Res. 19319

3. De Leon E J, Olmedo D A, Solis P N, Gupta M P, Terencio M C 2002 Planta Med. 681128

4. Hoang V D, Tan G T, Zhang H J, Tamez P A, Nguyen M C, Soejrto D D, Fong H H S, Pezzuto J M 2002 Phytochemistry $\mathbf{5 9} 325$

5. MacRae W D, Towers G H N 1984 Phytochemistry 23 1207

6. Brown R C, Bataille C J, Bruton G, Hinks J D, Swain N A 2001 J. Org. Chem. 666791

7. Iwakami S, Ebizuka Y, Sankawa U 1990 Heterocycles 30795

8. Ichikawa K, Kinoshita T, Nishibe S, Sankawa U 1986 Chem. Pharm. Bull. 343514

9. Nikaido T, Ohmoto T, Kinoshita T, Sankawa U, Nishibe S, Hisada S 1981 Chem. Pharm. Bull. 293586

10. Plante G E, Prevost C, Chainey A, Braquet P, Sirois P 1987 Am. J. Physiol. 253 R375 
11. Bernard C B, Arnason J T, Philogene B J R, Lam J, Waddell T 1989 Phytochemistry 281373

12. Najera C, Yus M 2003 Curr. Org. Chem. 7867

13. Takahashi K, Nakagawa T 1966 Chem. Pharm. Bull. 14 641

14. Tsukamoto H, Hisada S, Nishibe S 1984 Chem. Pharm. Bull. 322730

15. Tsukamoto H, Hisada S, Nishibe S 1985 Chem. Pharm. Bull. 331232

16. Xiaojun H, Corey E 1999 J. Org. Lett. 111871

17. Anjaneyulu A S R, Ramaiah P A, Row L R, Pelter A, Ward R S 1975 Tetrahedron Lett. 342961

18. Inoue K, Inoue H, Chen C C 1981 Phytochemstry 20 2271

19. Jung J C, Kim J C, Moon H I, Park O S 2006 Tetrahedron Lett. 476433

20. Kim J C, Kim K H, Jung J C, Park O S 2006 Tetrahedron: Asymmetry 173

Selected data; 7: mp. $124-126^{\circ} \mathrm{C}[\alpha]_{D}^{20}$ (c 1.0, MeOH); IR (neat, $\mathrm{NaCl}$ ) 1772, 1498, 1247, $1038 \mathrm{~cm}^{-1} ;{ }^{1} \mathrm{H}$ NMR $\left(300 \mathrm{MHz}, \mathrm{CDCl}_{3}\right) \delta 6.81(\mathrm{~s}, 4 \mathrm{H}), 6.75(\mathrm{~s}, 2 \mathrm{H})$, $5.99(\mathrm{~s}, 4 \mathrm{H}), 5.82(\mathrm{~s}, 2 \mathrm{H}), 3.54(\mathrm{~s}, 2 \mathrm{H}) ;{ }^{13} \mathrm{C} \mathrm{NMR}$ $(75 \mathrm{MHz}, \mathrm{CDCl} 3) \delta 175.3,149.2,149.0,132.4$, 119.2, 109.4, 105.9, 102.3, 82.5, 48.9; MS(ESI) (m/z) $383[\mathrm{M}+\mathrm{H}]^{+}, 307,154$ (base peak); HRMS calcd for $\mathrm{C}_{20} \mathrm{H}_{14} \mathrm{O}_{8}: 383.0767[\mathrm{M}+\mathrm{H}]^{+}$, found: 383.0695 . (-)-Wodeshiol 1: mp. $153-154^{\circ} \mathrm{C}$ (lit. ${ }^{16} 152-153^{\circ} \mathrm{C}$; lit. $\left.^{12} 150-151^{\circ} \mathrm{C}\right) ;[\alpha]_{D}^{20}=-11.2\left(\mathrm{c} 0.7, \mathrm{CHCl}_{3}\right)$, (lit. ${ }^{16}$ $[\alpha]_{D}^{23}=-11.7$ in $\mathrm{CHCl}_{3}$; lit. ${ }^{12}[\alpha]_{D}^{24}=-34.6$ in $\left.\mathrm{CHCl}_{3}\right)$; IR (neat, NaCl) 3432, 1602, 1256, $1032 \mathrm{~cm}^{-1} ;{ }^{1} \mathrm{H}$ NMR $\left(400 \mathrm{MHz}, \mathrm{CDCl}_{3}\right) \delta 6.8-6.6(\mathrm{~m}, 6 \mathrm{H}), 6.05(\mathrm{~s}, 4 \mathrm{H}), 5.13$ (s, 2H), 4.0-2.8 (m, 4H); $\left.{ }^{13} \mathrm{C} \mathrm{NMR} \mathrm{(100} \mathrm{MHz,} \mathrm{CDCl}_{3}\right)$ $\delta$ 149.0, 147.9, 128.3, 120.4, 108.8, 101.4, 87.3, 85.7, 76.3; HRMS calcd for $\mathrm{C}_{20} \mathrm{H}_{19} \mathrm{O}_{8}: 387.1080[\mathrm{M}+\mathrm{H}]^{+}$, found: 387.1091 . General procedure for the preparation of dihydroxy dilactone 6: To a stirred solution of diisopropylamine $(0.25 \mathrm{~mL}, 1.87 \mathrm{mmol}), \mathrm{n}-\mathrm{BuLi}(1.1 \mathrm{~mL}$, $1.87 \mathrm{mmol})$ in THF $(3 \mathrm{~mL})$ at $-78^{\circ} \mathrm{C}$ and dilactone 7 (300 $\mathrm{mg}, 0.83 \mathrm{mmol}$ ) was added to the reaction mixture at $-78^{\circ} \mathrm{C}$ and the mixture was stirred at same the temperature for $1 \mathrm{~h}$. The reaction mixture was treated with $\mathrm{MoOPH}(1.08 \mathrm{~g}, 2.49 \mathrm{mmol})$ at $-78^{\circ} \mathrm{C}$. As soon as the sparingly soluble reagent has resolved, the reaction was quenched with aqueous sodium sulfite and extracted with ether $(3 \times 10 \mathrm{~mL})$. The organic phase was washed with $5 \% \mathrm{HCl}$ and brine. The combined organic phase was dried over anhydrous $\mathrm{MgSO}_{4}$, filtered and concentrated under reduced pressure to give dihydroxy dilactone 6, which were purified by flash column chromatography (silica gel, 25\% ethyl acetate in hexanes) to afford pure dihydroxy dilactone $6(199 \mathrm{mg}, 58 \%)$ as a clean solution. IR (neat, $\mathrm{NaCl}$ ) 3329, 1780, 1488, $1042 \mathrm{~cm}^{-1}$; ${ }^{1} \mathrm{H}$ NMR $\left(300 \mathrm{MHz}, \mathrm{CDCl}_{3}\right) \delta 6.8(\mathrm{~m}, 6 \mathrm{H}), 6.3(\mathrm{~s}$, 2H), $6.0(\mathrm{~s}, 4 \mathrm{H}) ;{ }^{13} \mathrm{C} \mathrm{NMR}\left(75 \mathrm{MHz}, \mathrm{CDCl}_{3}\right) \delta 175.3$, 148.3, 147.3, 135.2, 120.9, 108.6, 101.4, 97.8, 83.7. HRMS calcd for $\mathrm{C}_{20} \mathrm{H}_{15} \mathrm{O}_{10}: 415.0665[\mathrm{M}+\mathrm{H}]^{+}$, found: 415.0652.

21. Evans D A, Bartoli J, ShiH T L $1981 \mathrm{~J}$. Am. Chem. Soc. 1032127

22. Van Horn D E, Masamune S 1979 Tetrahedron Lett. 24 2229

23. Vedejs E 1974 J. Am. Chem. 45944

24. Anjaneyulu A S R, Ramaiah P A, Row R, Venkateswarlu R, Pelter A, Ward R S 1981 Tetrahedron 373641 